\title{
Cuadernos LIRICO
}

Revista de la red interuniversitaria de estudios sobre las literaturas rioplatenses contemporáneas en Francia

\section{Juan Carlos Onetti : La escritura con propósitos}

\section{María Alejandra Alí}

\section{OpenEdition \\ Journals}

Edición electrónica

URL: http://journals.openedition.org/lirico/1115

DOI: 10.4000/lirico.1115

ISSN: 2262-8339

Editor

Réseau interuniversitaire d'étude des littératures contemporaines du Río de la Plata

Referencia electrónica

María Alejandra Alí, « Juan Carlos Onetti : La escritura con propósitos », Cuadernos LIRICO [En línea]

9 | 2013, Puesto en línea el 01 septiembre 2013, consultado el 30 abril 2019. URL : http:// journals.openedition.org/lirico/1115; DOI : 10.4000/lirico.1115

Este documento fue generado automáticamente el 30 abril 2019.

\section{(c) (1) (9)}

Cuadernos LIRICO está distribuido bajo una Licencia Creative Commons Atribución-NoComercialSinDerivar 4.0 Internacional. 


\title{
Juan Carlos Onetti : La escritura con propósitos
}

\author{
María Alejandra Alí
}

\section{Introducción}

1 Abordaremos un aspecto del proceso de escritura de la novela Juntacadáveres(1964) de Juan Carlos Onetti desde la perspectiva de la genética textual : en esta ocasión nos centraremos en la forma en que el autor elabora el comienzo de la narración. Hemos consultado los borradores de la novela en el Archivo literario de la Biblioteca Nacional de Uruguay donde observamos que los tipos de pre-texto utilizados por Onetti incluyen manuscritos autógrafos (son aquellos escritos manualmente por el autor) y mecanoscritos corregidos a mano. Si bien todo texto supone un pre-texto (aunque sea mental), no todos los escritores acuden a planes previos a la textualización. Suponemos que Onetti pudo haber empleado esquemas sinópticos que apuntalaran la construcción de los capítulos, y de hecho en el curso de nuestro trabajo de investigación en el archivo del autor encontramos un documento de este tipo, que si bien aparece aislado permite sospechar la existencia de otros. Basamos nuestra suposición en la firmeza con la que inscribe en los borradores fragmentos centrales de cada capítulo que luego sufren escasas transformaciones, ligadas fundamentalmente a la adjetivación o a los tiempos verbales, lo que nos hace pensar en un proyecto mental muy claro que probablemente el autor haya plasmado en primera instancia a través de una escritura programática, la que luego daría lugar a una primera de carácter redaccional inscripta en lápiz, sucedida por la inscripción manuscrita en tinta. ${ }^{1}$

\section{Características de los manuscritos de Onetti}

Bueno, quiero decir si escribe con un plan que elabora previamente. Si sabe exactamente adónde va a llegar.

Sé qué va a pasar. No sé cómo va pasar. Si supiera cómo va a pasar no lo escribiría. ${ }^{2}$ 
2 Entre los pre-textos de Juntacadáveres reunidos en la Colección Onetti se encuentra un conjunto de hojas sueltas pertenecientes a distintos cuadernos y arrancadas luego, un cuaderno completo y una serie de dactiloscritos ordenados según el criterio de la encargada de la edición del tercer tomo de las obras completas de Onetti, Hortensia Campanella. El registro del proceso de escritura consignado en el cuaderno completo, de tapas duras, 200 hojas, industria argentina, supone un notable grado de avance en el proceso genético ya que contiene versiones de los dos primeros capítulos de la novela muy similares a las del texto publicado. En el presente trabajo nos concentraremos en el análisis de ese pre-texto de la novela, remitiéndonos a su relación con los borradores que le anteceden, escritos en lápiz, y los que lo suceden, pasados a máquina.

Dicho cuaderno, titulado del Prostíbulo, contiene los principales núcleos de la novela desplegados narrativamente, es decir, en una etapa redaccional ya encaminada a textualizar. Los elementos narrativos allí consignados son : los dos primeros capítulos de la novela, que describen el regreso de Larsen a Santa María en compañía de las tres mujeres elegidas para integrar el burdel ; los encuentros entre Marcos y Rita, espiados por Jorge Malabia; la puesta en escena del cura Bergner para influir en los feligreses instándolos a combatir el mal (pp. 124-125)³ ; la redacción de los anónimos (pp. 179 y ss.), las actividades programadas por la liga de la Decencia, o liga de Caballeros (desplegados en el capítulo XX de la novela); y una descripción de Julia Bergner, tal como pasará al penúltimo párrafo del capítulo XXV, p. 228.Como se advierte, en esos núcleos narrativos están esbozados los principales ejes de la trama narrativa de la novela : la « aventura prostibularia » de Larsen, la reacción de la Liga de Caballeros que vigilará las actividades del prostíbulo, la actuación del cura Antón Bergner y el papel de los anónimos redactados por las señoritas de la Acción Cooperadora (católica). Y por otra parte, la loca historia de amor entre Jorge Malabia y la viuda de su hermano Federico, Julia Bergner.

Si bien no hay muchos testimonios de Onetti en torno de la creación de sus novelas y cuentos, consideraremos aquí sus declaraciones más reveladoras, en las que confió a sus entrevistadores ciertos secretos acerca de los procesos de escritura. En esos casos los citamos como epígrafe o los incluimos en el desarrollo con la referencia correspondiente. Analizaremos especialmente el plano de Santa María diseñado por Onetti ${ }^{4}$, ya que el boceto de la ciudad crea ese mundo: el croquis diseña los espacios donde residen, trabajan, gozan, aman y sufren los personajes, desde y hacia donde se desplazan según los designios de su autor. El croquis de Santa María materializa la imagen mental de ese micro-mundo que van a habitar los personajes. Presumimos que la novela soporta el peso de la construcción del universo onettiano : en La vida breve, el guionista de cine crea el espacio diseñando la ciudad ; en Juntacadáveres, una novela posterior en catorce años, se plasma ese mundo: los personajes que van a impulsar y desplegar ese universo novelístico. Si tomamos en cuenta que los procesos de escritura pueden clasificarse básicamente en dos tipos, la escritura programada donde diversas instancias previas a la etapa redaccional señalizan la ruta creativa del mundo ficcional y, en contraposición, la escritura en proceso, que se va desarrollando en el devenir a través de la inscripción de numerosas versiones que trazan el proceso de escritura, dejamos planteado el interrogante acerca del carácter de los procesos de construcción ${ }^{5}$ en Onetti, sostenidos por los sistemas de transcripción, de copia y pasado en limpio observados en los borradores. Es preciso agregar que los borradores consultados, en particular el cuaderno del Prostíbulo, tienen pocas enmiendas : allí la escritura parece encaminarse segura hacia la versión definitiva del texto. 


\title{
La invención de Santa María
}

\author{
Santa María no existe más allá \\ de mis libros, si existiera \\ realmente, si pudiera vivir, \\ o viviera allá, inventaría una \\ ciudad que se llamara \\ Montevideo. ${ }^{6}$
}

5 En uno de los capítulos de Juntacadáveres, una digresión del narrador referida a los acontecimientos evocados en la trama narrativa permite entrever la fase del proyecto mental de un proceso creativo. ${ }^{7}$ El relieve que presenta esa interrupción del relato justifica la reproducción in extenso de ese fragmento del texto publicado :

De todo esto hace años, ya se sabe. Ahora podemos creer, al evocarlos, que estamos viendo a Santa María y a sus habitantes tal como eran y no como nosotros los vimos entonces. Nada esencial nos une ya con lo que recordamos; pero, fundamentalmente, esta distancia no la proporciona el tiempo sino el desinterés.

El terreno de Santa María no tiene ninguna elevación de importancia ; la ciudad, la Colonia, el paisaje total que puede descubrirse desde un avión, baja sin violencia, llenando un semicírculo hasta tocar el río ; hacia el interior, la tierra es llana y pareja, sin otra altura notable que la de los montes. $Y$, sin embargo, ahora, al contar la historia de la ciudad y la Colonia en los meses de la invasión, aunque la cuente para mí mismo, sin compromiso con la exactitud o la literatura, escribiéndola para distraerme, ahora, en este momento, imagino que hay un cerro junto a la ciudad y que desde allí puedo mirar casas y personas, reír y acongojarme; puedo hacer cualquier cosa, sentir cualquier cosa ; pero es imposible que intervenga y altere.

También imagino a Santa María, desde mi humilde altura, como una ciudad de juguete, una candorosa construcción de cubos blancos y conos verdes, transcurrida por insectos tardos e incansables. Veo entonces la diminuta población y entiendo su forma geométrica, sus alturas, su equilibrio; entiendo, por su casi invariable reiteración, los móviles que determinan la inquietud de los insectos ; pero no puedo descubrir un sentido indudable para todo esto y me asombro, me aburro, me desanimo. Cuando el desánimo debilita mis ganas de escribir -y pienso que hay en esta tarea algo de deber, algo de salvación - prefiero recurrir al juego que consiste en suponer que nunca hubo una Santa María ni esa Colonia, ni ese río.

Así, imaginando que invento todo lo que escribo, las cosas adquieren un sentido, inexplicable, es cierto, pero del cual sólo podría dudar si dudara simultáneamente de mi propia existencia. Nunca antes hubo nada o, por lo menos, nada más que una extensión de playa, de campo, junto al río. Yo inventé la plaza y su estatua, hice la iglesia, distribuí manzanas de edificación hacia la costa, puse el paseo junto al muelle, determiné el sitio que iba a ocupar la Colonia.

Es fácil dibujar un mapa del lugar y un plano de Santa María, además de darle nombre; pero hay que poner una luz especial en cada casa de negocio, en cada zaguán y en cada esquina. Hay que dar una forma a las nubes bajas que derivan sobre el campanario de la iglesia y las azoteas con las balaustradas cremas y rosas; hay que repartir mobiliarios disgustantes, hay que aceptar lo que se odia, hay que acarrear gente, de no se sabe dónde, para que habiten, ensucien, conmuevan, sean felices y malgasten. $Y$, en el juego, tengo que darles cuerpos, necesidades de amor y dinero, ambiciones disímiles y coincidentes, una fe nunca examinada en la inmortalidad; tengo que darles capacidad de olvido, entrañas y rostros inconfundibles. (Capítulo XX, pp. 183-184)

6 Entremedio de un capítulo que narra la actividad de la Liga de Caballeros $^{8}$ ,complementada con el envío de anónimos, aflora una reflexión sobre la actividad 
creadora que parece rasgar la superficie del texto dejando ver lo que hay por debajo ; en medio de una panorámica mirada sobre la actuación de los personajes de Santa María en la época en que Larsen volvió a la ciudad e instaló el prostíbulo, aludida como « los meses de la invasión ", repentinamente aparece esta referencia, atribuida a la narración de Jorge Malabia, y que sin embargo confunde los órdenes de la creación de espacio y tiempo casi como si se disolviera -confundiéndose - con La vida breve en lo atinente a la fundación de Santa María por Brausen. El comentario, desarrollado a lo largo de una página del texto édito, parece una incrustación en el medio del relato y se presenta como una saliente que hace posible acceder a un plano profundo de los procesos de construcción. ${ }^{9}$ Por otra parte, agregamos que en una entrevista concedida a la Radio Televisión española en 1976, Onetti contó que en medio del proceso de escritura de Juntacadáveres se le ocurrió la muerte de Larsen, escena con la que culmina El Astillero. Esa invasión de la novela futura, según la opinión del autor conspiró contra la tensión narrativa de Juntacadáveres, debilitando la segunda mitad de la novela. Si bien la apreciación es válida como testimonio del escritor, nos permitimos sugerir que la idea para una nueva novela le habría permitido darle un fin a la que estaba en curso, como ocurre en otros escritores, tal el caso de Ricardo Piglia, que sobre el final de un proceso de escritura suele delinear un nuevo proyecto, con menos nostalgia de la escritura por finalizar. Precisamente Onetti se refirió a la tristeza que le provocaba la conclusión de un proceso creativo en el mencionado reportaje.

7 Resulta notable que en la evocación surgida en el citado capítulo de Juntacadáveres, el narrador mira la ciudad y la describe como si fuera una maqueta: cubos blancos, conos verdes, muy similar a las miniaturas con que los arquitectos proyectan un edificio, un paisaje, una construcción. Por una parte notamos que este segmento narrativo alude al croquis de Santa María realizado de mano del autor que -tal y como señala Daniel Balderston en la edición de las Novelas cortas de Onetti de la Colección Archivos- fue encontrado en una carpeta etiquetada con el título de Juntacadáveres (aunque en el interior había manuscritos de otros procesos textuales). Este fragmento novelístico se comporta como un epígrafe del diseño de la ciudad; por otro lado, resaltamos que el boceto de Santa María resalta por su peculiaridad entre los borradores de un autor en los que no abundan los diagramas, ilustraciones ni esquemas, lo que estaría señalando la unicidad y la relevancia de ese elemento en su universo creativo.

8 El nombre de la ciudad consolida el espacio del universo onettiano a la vez que provoca perplejidades, ya que en uno de los folios mecanoscritos pertenecientes a una etapa avanzada de composición de la novela, Santa María aparece mencionada repetidas veces con el nombre de Cruz Alta, nombre tachado manualmente y reemplazado por el de Santa María en agregado interlineal. Santa María había sido fundada en La vida breve y teniendo en cuenta el armazón del universo onettiano que hace circular a sus personajes principales entre las diversas tramas novelísticas, resalta aún más la indecisión en el nombre. Probablemente ello se deba a que la opción considerada, Cruz Alta, estaría más vinculada con la tensión que sustenta la novela: la agonía entre el bien y el mal provocada por el comercio erótico consentido en la casita celeste.

\section{Las réplicas de Larsen}

9 La gran fuerza narrativa de la novela, la energía que la impulsa, es el proyecto de Larsen de instalar un prostíbulo en Santa María, vivido por el personaje como un desquite de 
viejas aspiraciones juveniles. El regreso de Larsen -Juntacadávere ${ }^{10}$ a la ciudad, plasmado en los borradores, es formulado y sometido a correcciones, rescrito intensamente hasta encontrar un equilibrio en la presentación del regreso del protagonista. El retorno del héroe se va disponiendo con la complementariedad necesaria de un antagonista que actuará como resistencia a su proyecto, percibido como una penetración del demonio en Santa María, y a la vez como una oportunidad para el arrepentimiento y la redención de los pecadores. En los borradores redaccionales, las descripciones del proyecto de Junta y de las mujeres que lo acompañan en esa travesía resultan contrapesadas con la reacción que provoca la casa del pecado instalada en la costa : los sermones del cura Bergner, los anónimos redactados y escritos por las señoritas del pueblo, la vigilancia sobre la casita ejercida por los hombres de la Liga de Caballeros por la decencia, se alternan durante el proceso constructivo de la novela; el binomio Bien/Mal sustenta la arquitectura de Juntacadáveres. Al registrar las dos fuerzas que sostienen el equilibrio interno de la trama argumentativa, tanto al plasmar el proyecto del prostíbulo como al esbozar las posibles razones por las cuales el cura Bergner se manifiesta moroso (Onetti emplea el adjetivo "tardo") en su decisión de intervenir en semejante despropósito para el orden social de la ciudad, el autor esboza con sumo detalle la postura corporal de cada uno. Reproducimos más abajo dos versiones de la descripción de Larsen que figuran en el cuaderno del Prostíbulo, la primera atravesada por una tachadura diagonal que abarca toda la página indicando que el texto ha sido copiado, es decir, pasado en limpio; la segunda, con algunas variaciones, rescrita en tinta en el mismo cuaderno; en la tercera columna se reproduce el íncipit de la novela en el texto édito :

\begin{tabular}{|c|c|c|}
\hline $\begin{array}{l}\text { Lustroso y resoplante, Junta } \\
\text { fue a } \\
\text { sentarse con las tres } \\
\text { mujeres... }\end{array}$ & $\begin{array}{l}\text { Resoplando y lustroso, } \\
\text { perniabierto sobre los saltos } \\
\text { del } \\
\text { vagón en el ramal de Enduro, } \\
\text { Junta caminó por el pasillo } \\
\text { para } \\
\text { agregarse al grupo de tres } \\
\text { mujeres, algunos kilómetros } \\
\text { antes } \\
\text { de que el tren llegara a Santa } \\
\text { María. }\end{array}$ & $\begin{array}{l}\text { Resoplando y lustroso, } \\
\text { perniabierto sobre los saltos } \\
\text { del } \\
\text { vagón en el ramal de Enduro, } \\
\text { Junta caminó por el pasillo } \\
\text { para } \\
\text { agregarse al grupo de tres } \\
\text { mujeres, algunos kilómetros } \\
\text { antes } \\
\text { de que el tren llegara a Santa } \\
\text { María. }\end{array}$ \\
\hline
\end{tabular}

Para caracterizar al cura Bergner, un pre-texto mecanoscrito donde se esboza la escena en la que la Liga de Caballeros por la Decencia cita a Marcos Bergner a la Iglesia, sugiere :

El otro ramal de la explicación confusa nos lleva a un padre Bergner que quiso, aceptó, permitió la llegada y el afincamiento del mal para que los habitantes de Santa María y la colonia, las ovejas que le habían sido confiadas, tuvieran su colectiva, patente oportunidad de tentación...

11 Resulta sugestivo que los adjetivos calificativos de Larsen lo asimilen con el tren que lo trae de vuelta a Santa María, lustroso y resoplante; por su parte, las conjeturas acerca de la inacción del cura confluyen en el sustantivo "ramal », que alude al tramo ferroviario (el ramal de Enduro) del tren que conducía a todo el grupo. Señalamos este aspecto de la construcción de los personajes porque varios de ellos, como el cura y su sobrino Marcos Bergner, parecen recortados del perfil de Larsen, como si fuera una filigrana, ya que 
adoptan ciertas características del otro a través de un juego de oposiciones. La configuración de la trama novelística fluctúa entre las borrosas explicaciones acerca de la instalación del prostíbulo en Santa María, lo cual se observa en el devenir-texto de la novela donde se alternan la imagen mental de la casa de citas y la letra del sermón del Cura Bergner (de ahí tal vez la condensación en la casita celeste que nombra al prostíbulo en el texto édito). La voz narrativa resalta lo asombroso e inexplicable de la inacción del cura, sugerido mediante un paradigma de opciones que conjeturan acerca de sus motivaciones confluyendo en el término « ramal » que resultaría más apropiado de otro campo semántico. La insistencia en una misma palabra usada en la segunda ocasión en un contexto inadecuado, resalta la intensidad de Larsen, que funciona como un imán en la construcción de su figura opuesta, Antón Bergner. La lectura de los borradores permite observar cómo la historia se construye en contrapunto entre la ideación del prostíbulo, un escándalo en la pequeña ciudad, y las palabras que organizan los sermones del cura, en su intento de restablecer el orden social y moral en la pequeña población.

El domingo de Santa Eulalia el cura Bergner estuvo inmóvil un largo rato antes de empezar el sermón, los brazos caídos, erguido con agobio el gran cuerpo atlético, paseando los ojos, como si buscara, por los rostros que llenaban la iglesia. (...) El cura hablaba lento, doblados los grandes hombros, sostenidos por las manos que se encorvaban, adelantadas, imponiendo una magnitud asombrosa, una distancia increíble entre ellas y el sufrimiento pálido de la cara. Trabajosamente, enderezó el cuerpo, se acercó las manos con una sonrisa de melancolía y burla. (...) Nuevamente estaba separado del púlpito, las manos caídas, la cabeza torcida, la enorme figura inclinada hacia adelante, como si estuviera a punto de bambolearse y caer, como si la solidez, la energía, la salud del ancho cuerpo estuvieran amenazadas por una enfermedad repentina y sin remedio. (pp. 124, 125, 126)

La escena con la que se abre la novela ubica en primer plano a Larsen regresando a Santa María por la tan esperada revancha, aun a sabiendas de que podría ser tarde para sus propósitos : en su caso, la exultación de su actitud vindicativa contrasta con la decrepitud del cuerpo; inversamente, en la caracterización del cura la enorme contextura física alterna con una impostada fragilidad destinada a impresionar a los acólitos, al punto de que en una misa su cabeza semeja la del cadáver de la joven asesinada en La cara de la desgracia, como si en cualquier momento fuera a desprendérsele del torso. Hay contrastes en la construcción de los personajes, manifestados en discrepancias tales como la tenaz oposición de Marcos Begner al prostíbulo, como también fusiones derivadas de la contaminación entre personajes (Marcos - Larsen y Jorge Malabia - Marcos Bergner, el parecido entre estos dos últimos está sugerido en un diálogo entre Lanza y Malabia). En el caso de Marcos Bergner, los borradores de la novela consignan que « su tío debía estar ya enterado de su particular aventura prostibularia ». En parte esa referencia cruzada entre Larsen y Marcos puede atribuirse a los antecedentes de éste, uno de los artífices y protagonistas de la experiencia del Falansterio ${ }^{11}$, que a su modo también proponía una ruptura del orden social, aunque considerando que la experiencia iniciada en Santa María por cinco parejas de la clase alta se vio muy pronto desbordada por la conducta sexual de Marcos Bergner, resalta aún más lo contradictorio del personaje, tal como el viejo Lanza le señala a Jorge Malabia.(ver capítulo XVI) 


\section{La invasión}

13 Como hemos apuntado al enumerar las unidades narrativas consignadas en el borrador redaccional de la novela (cuaderno del Prostíbulo), allí se inscribe uno de los anónimos -el segundo - que circularán por Santa María. A continuación lo transcribimos :

[<Protección Divina>]

Alianza con el demonio y con judíos puede parecer un buen negocio. Pero la Đivina Providencia se

aleja de nosotros. Piense en los ahogados de la Rinconada. Medite y despierte."

Puede asegurarse

que éste fue el anónimo número dos, una variante del primeroque, más desenfadado, más

enardecido, podemos considerar como primero. Para qué la Iglesia si hay un lenocinio. Para qué un

hogar si las

$[<\mathrm{a}>$ ]

mujeres se alquilan por diez pesos. Cuando un pueblo pierde el sentido de la decencia es justo que

[<Divina Protección>]

pierda también la Protección Divina. Los ahogados de la Rinconada inician la serie de desgracias.

Esta variante textual pasará sin modificaciones al capítulo XIII del texto editado. En el verso de la página manuscrita donde está la anotación, renglón final, se lee la referencia : Biblia 490, Invasión. En el fragmento del capítulo XX citado con anterioridad, el sintagma « la invasión » alude a la aventura prostibularia en Santa María, como ya hemos señalado. Una anotación en la contratapa del cuaderno con una lista de elementos para la trama novelística, escrita en lápiz negro, incluye el sintagma « La apostasía de Dios (infieles) » ${ }^{12}$. Nos detenemos en esta referencia por el peso que tiene en la construcción de la trama. La fuerte oposición entre el Bien y el Mal inherente a los escritos bíblicos se convierte en un elemento articulador de la novela y, dentro de las microestructuras, en la oposición binaria que organizará los anatemas del cura Bergner para intentar restablecer el equilibrio en la vida de los habitantes de Santa María, la que poco antes del regreso de Larsen ha sido declarada ciudad. No resulta ajeno a ese cambio de estatus político el que Santa María se vea amenazada por los vicios, tentaciones y deslices que caracterizan a las grandes ciudades. La apostasía, que implica una vida de pecado, es una parte constitutiva de la aspiración de crear el prostíbulo perfecto, un viejo empeño que respondía a una temprana y juvenil afición de Larsen por vivir de las mujeres. El capítulo XIV de la novela narra la génesis de esa propensión :

Al principio había sido aquella grosera cosa, aquel oficinista de veinte años que trataba de satisfacer un orgullo, también grosero, instintivo, con todo lo que pudiera obtener gratis de las mujeres. (...) Entonces conoció a María Bonita y estuvo seguro de que la realización de los ideales depende del grado de renunciamiento de que seamos capaces; esta seguridad se transformó luego en dogma y no habría de abandonarlo durante el resto de su vida. (pp. 128, 133)

La concepción del sueño de Larsen se esboza en uno de los folios mecanoscritos :

Al final de los seis meses, él pensó que había nacido para realizar dos perfecciones una

[<mujer>]

prostitutaperfecta, un prostíbulo perfecto. Para el primer ideal necesitaba la complicidad de 
la providencia, el encuentro con la hipotética muchacha nacida para tal destino, para el

segundo era imprescindible tener dinero y las manos libres. ${ }^{13}$

Larsen se percibe como un hacedor en su deseo creador de ese mundo que se manifestará como la expresión del pecado. Como ha señalado Fernando Aínsa : « Ese mundo inventado supone una geografía propia y el manejo de personajes cuya composición social es típicamente marginal (lumpen, 'detraquées', prostitutas y fracasados) ». ${ }^{14}$ Para contrapesar ese mundo, en el cuaderno del Prostíbulo surge el interrogante acerca de cómo concluir la prédica del padre Bergner, es decir, qué forma y sentido darle a la reprimenda del cura a los feligreses por haber abandonado el camino de Dios. Se plantea « ¿Cómo termina un cura el sermón? », con el que Bergner se enfrentará con ese espacio creado por Larsen, paradójica o irónicamente denominado « casa celeste ».La oposición constitutiva de la novela se advierte en los núcleos narrativos delineados en el cuaderno : el proyecto del Prostíbulo es una ocasión para que Santa María pueda diferenciar el bien del mal, es decir, combatir el peligro de la apostasía incitada por la aventura prostibularia de Larsen y sus efectos dañinos sobre los hombres de la ciudad.

Por otra parte, en la carátula del cuaderno aparecen dos inscripciones que encabezan e hilvanan la escritura de la novela : en primer lugar se despliegan las primeras líneas de la plegaria a la virgen María reiteradas en diversas etapas de escritura bajo la forma de una larguísima sigla. La disposición de esa sigla que semeja un abecedario por su estructura y extensión se desplegará a lo largo del proceso genético de la novela (AMLEDGESECBTEETLMYBEFDTVJ). Reproducimos a continuación tal como aparece el registro en el borrador, en forma de verso :

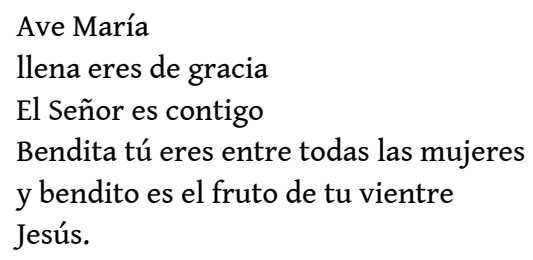

18 Y luego : "Extiéndase la alegría y penetre como polvo de malicia, dicha, ferocidad (dientes en la sonrisa y la rabia)» [el resaltado me pertenece]. Se apunta más abajo una directriz del proceso de escritura, y a continuación la redacción del primer capítulo de la novela ; la auto-indicación tiene el carácter de una máxima, por lo cual podría extendérsela a otros procesos de escritura de Onetti : « Los diálogos, espacios para respirar. Un párrafo, dos notas de belleza, una de violencia " [el resaltado me pertenece].La sugerencia escrituraria tiene importantes consecuencias en la poética onettiana, ya que en las supresiones y modificaciones observadas se advierte una tendencia a suavizar la crueldad o la crudeza de las descripciones, a otorgarles un tinte de piedad, de compasión o de empatía hacia los personajes que atenúe la dureza con la que se los había caracterizado. Lo que el autor registra en tinta en las primeras páginas del cuaderno del Prostíbulo es una versión parcial de algunos capítulos de la novela. El pasaje de la larga sigla que encabeza el grupo de dactiloscritos -una etapa más avanzada del proceso de escritura - a la inscripción de la oración a María promueve e impulsa una variante textual de la novela muy semejante a la versión final. Todo indica que la copia en limpio de los primeros capítulos de la novela y de los núcleos narrativos que la estructuran promueve el avance de la escritura. ${ }^{15}$ 


\section{A modo de envío}

La manifiesta preferencia del escritor por consignar las anotaciones propias del proceso genético a través de la secuencia lápiz negro - tinta azul nos ha parecido afín con los antiguos sistemas de enseñanza de la escritura en la educación primaria en Argentina y por extensión en el Río de la Plata, donde el empleo de la pluma quedaba reservado para una etapa de mayor dominio en el aprendizaje de las primeras letras. La indagación de los vínculos entre los soportes de escritura, los útiles e instrumentos elegidos y empleados que excede largamente las líneas del presente trabajo - formará parte de un proyecto de investigación donde interrogaremos la correlación entre los instrumentos materiales y los géneros o subgéneros literarios (cuento, nouvelle o novela).

21 El cuaderno como lugar cerrado, de recepción y cobijo de la escritura, la pone a resguardo mucho más que la volátil hoja suelta, siempre en peligro de perderse o mezclarse y confundir así la génesis de diversos proyectos después de días y meses de trabajo. Según el testimonio del propio escritor y de sus allegados y colaboradores, eso sucedió con el proceso de escritura de diversos textos de Onetti. Consideramos que la concentración en un espacio cerrado, autónomo y a la vez protegido, como el cuaderno de tapa dura que ha albergado el proyecto del Prostíbulo, ha tenido sus efectos y consecuencias sobre la estructuración de la novela, al constituirse en el espacio cerrado donde se desarrolló y conservó un proyecto de escritura definido, con propósitos, aun a pesar de los dichos y los mitos del escritor.

Nunca se perdió en Santa María ? ¿Nunca hizo planos ni genealogías?

Una vez hice un plano de Santa María con un amigo, pero era sólo para mover mejor a los personajes. Lo perdí cuando me vine de Buenos Aires. A mí se me ocurre escribir una novela, y ya tiene su lugar en Santa María. Pero nunca me propuse desarrollar un plano. $\mathrm{O}$ sea : nunca quise escribir una saga. Ese es ya un propósito, y yo no podría escribir con propósitos. (Entrevista con Alfredo Barnechea) 


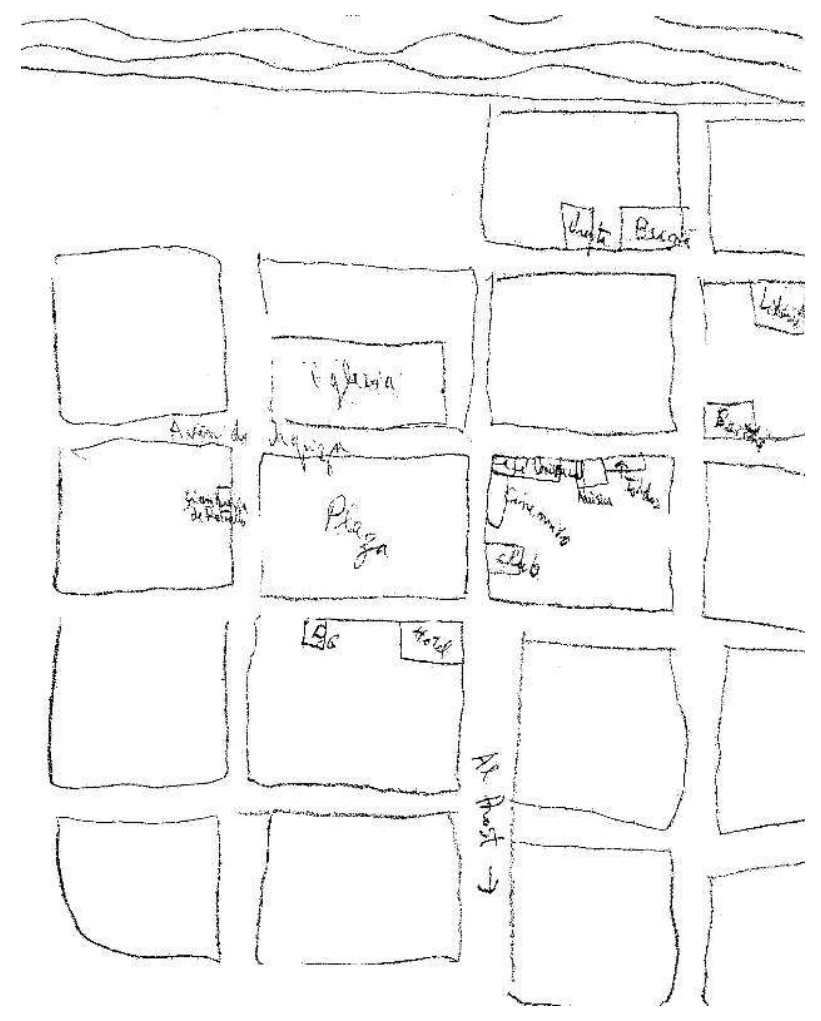

\section{BIBLIOGRAFÍA}

Aínsa, Fernando. Las trampas de Onetti. Biblioteca Virtual Universal. Edición digital basada en la de Alfa. (Montevideo, 1970). Disponible en : www.biblioteca.org.ar/libros/300297.pdf.

Barnechea, Alfredo. "Entrevista a Juan Carlos Onetti”. En Peregrinos de la lengua, Alfaguara, 1973 y El Mundo, 10 de agosto de 2001.

Brando, Oscar. « De Arlt a Onetti : camas desde un peso ». Cuadernos LIRICO [En línea], 8, 2013. Puesto en línea el 01 enero 2013, consultado el 11 marzo 2013. URL : http://lirico.revues.org/968. Bustarret, Claire. « Découpage, collage et bricolage : la dynamique matérielle du brouillon moderne ». En : Roelens, Nathalie et Yves Jeanneret. L'Imaginaire de l'écran/Screen Imaginary. New York : Rodopi, 2004, pp. 109-120. Disponible en http://www.item.ens.fr/index.php?id=23614.

De Biasi, Pierre-Marc. « Pour une analyse scientifique des manuscrits » (2007).Disponible en : http://www.item.ens.fr/index.php?id=13596.

Gresillon, Almuth. La mise en œuvre. Itinéraires génétiques. Paris : CNRS Éditions, 2008.

Gilio, María Esther. "Un monstruo sagrado y su cara de bondad" [entrevista con Juan Carlos Onetti], La Mañana, Montevideo, 20 de agosto de 1965.

Hay, Louis. « Le texte n'existe pas ». En Poétique, Paris, Seuil, nº 62, 1985, pp. 147-158. 
Hay, Louis. «Critiques du manuscrit ». En : La naissance du texte. Paris : José Corti, 1989.[En línea desde el 29 de enero de 2007].Disponible en :http://www.item.ens.fr/index.php?id=27141.

Lebrave, Jean-Louis. « Lecture et analyse des brouillons ». En : Almuth Grésillon y J. L. Lebrave, (eds.), Langages, Paris, Larousse, ${ }^{\circ}$ 69, marzo de 1983, pp. 11-23. Disponible en : http:// www.item.ens.fr/index.php?id=187203.

Onetti, Juan Carlos. Juntacadáveres. Montevideo : Santillana Ediciones, Colección Punto de lectura, 2007 [1964].

Onetti, Juan Carlos. Novelas cortas. (Daniel Balderston Coord.). Colección Archivos, ํㅜ 59, Universidad de Poitiers-Alción Editora, 2009.

Onetti, Juan Carlos. Obras completas. Ed. de Hortensia Campanella, Barcelona : Galaxia GutenbergCírculo de Lectores, 2006.

Soler Serrano, Joaquín. "Juan Carlos Onetti en A fondo", entrevista realizada en Escritores en el Archivo de RTVE el 26 de septiembre de 1976. Disponible en : www.rtve.es.

\section{NOTAS}

1. En el proceso de escritura de Juntacadáveres la secuencia en el uso de los útiles de escritura es lápiz-tinta.

2. Juan Carlos Onetti -María Esther Gilio, "Un monstruo sagrado y su cara de bondad”, La Mañana, Montevideo, 20 de agosto de 1965.

3. Citamos por la edición de Punto de lectura (Montevideo, 2007).

4. La imagen del plano de Santa María -que reproducimos junto con el artículo- integra los documentos presentados en la edición de las Novelas cortas de Onetti de la Colección Archivos, y ha sido analizada en la Introducción del Coordinador, Daniel Balderston.

5. Como los designó Josefina Ludmer en su iluminadora lectura. Ver Onetti. Los procesos de construcción del relato. [1977] Buenos Aires : Eterna Cadencia, 2009.

6. En una hoja suelta de libreta, lisa, Onetti anota esta frase. La notita, registrada en papel blanco, se encuentra en la carpeta con manuscritos de su novela Juntacadáveres, en la Colección Onetti del Archivo literario de la Biblioteca Nacional de Uruguay y ha sido una respuesta frecuente del autor cuando lo interrogaban acerca del universo de sus novelas.

7. Uno de los fundadores de la crítica genética, Louis Hay (1989), apela a la metáfora de romper el vidrio del texto para introducirse en las profundidades del proceso creativo. La imagen resulta muy apropiada para pensar en el análisis de las novelas de Onetti, puesto que ellas conservan en la superficie de la trama argumental algunos indicios de su génesis como ventanas que permiten espiar el proceso de composición y se manifiestan bajo la apariencia de una incrustación en el texto, a través de una frase, un párrafo o una unidad discursiva mayor que remite a una inestabilidad en la constitución del sentido.

8. Hay diez folios de mecanoscritos -agrupados en una serie de carpetas en el Archivo de Onettidedicados a la preparación del capítulo en el que la Liga de Caballeros por la Decencia cita a Marcos Bergner en la Iglesia.

9. Conjeturamos que la aparente fusión entre el papel de Brausen en la primera novela de Onetti y este afloramiento de la perspectiva narrativa en Juntacadáveres puede deberse a una contaminación de los procesos de escritura de ambos textos, dado que en los estudios de génesis se observa con frecuencia esta contingencia. De hecho, este desplazamiento e insistencia en la fundación de ese espacio casi mítico de Santa María de una novela a otra intensifica la cohesión de las tramas novelísticas de Onetti como ya ha señalado la crítica. 
10. El apodo que recibe el personaje proviene -precisa y casi paradójicamente -de su afán coleccionista de mujeres de la vida, en franca decadencia física y moral. La caracterización de las prostitutas como cadáveres y la cínica mirada de Larsen se advierten principalmente en los capítulos IX, XIV y XXII de la novela édita.

11. Falansterio es el nombre que recibieron las comunidades teorizadas por el socialista utópico francés Charles Fourier. Se fundaban en la idea de que cada individuo trabajaría de acuerdo con sus pasiones y no existiría un concepto abstracto y artificial de propiedad, privada o común. Los falansterios son comunidades rurales autosuficientes, que serían la base de la transformación social, creadas por acción voluntaria de sus miembros y compuestas por no más de 1.600 personas, que vivirían juntas en un edificio con todos los servicios colectivos. Todas las personas serían libres de elegir su trabajo, y lo podrían cambiar cuando quisieran. Todo estaba reglado y pensado para una vida cómoda y con el mayor placer ; incluso el amor y el sexo debían seguir un orden muy particular.

12. El sentido religioso de apostasía es de origen bíblico. Señala en sentido amplio rebelión contra Dios. Es decir, no obedecerlo ya sea por seguir falsos dioses (la idolatría) o desviación moral de la Ley. Las causas de la apostasía pueden incluir la enseñanza de falsos maestros, y la adopción de una vida de pecado promovida por los herejes, la persecución y la tentación satánica. Frente al peligro de la apostasía los autores apostólicos presentaban un antídoto: la exhortación de perseverar hasta el fin; estar firmes y retener la doctrina apostólica, retener la confianza en Dios, y resistir al diablo en la confianza de que Dios fortalece a su pueblo frente a las adversidades que pueden llevarlo a la apostasía.

13. Se trata de uno de los mecanoscritos agrupados en la carpeta JCO D 14-2.

14. Ese rasgo lo emparienta con Roberto Arlt. Sobre la influencia que la lectura de Arlt tuvo en la escritura onettiana, en particular en la arquitectura de la ciudad, puede consultarse el artículo de Oscar Brando «De Arlt a Onetti : camas desde un peso». Cuadernos LIRICO [En línea], 8, 2013. A partir del estudio de los manuscritos podemos añadir las resonancias arltianas en el bosquejo de la llegada a Santa María de María Bonita, Nelly e Irene, las prostitutas que acompañan a Larsen, sugerida por el paradigma sintagmático "La sucia expectación" y "La puerca espera", que remite al título concebido por Arlt para El juguete rabioso, "la vida puerca”. Hay más parentescos con Los siete locos : Larsen parece resultar de una confluencia entre Erdosain y el Rufián Melancólico.

15. Nos referimos a la copia en tinta en el cuaderno del Prostíbulo de las hojas escritas a lápiz y arrancadas de un cuaderno de espiral -un borrador anterior.

\section{RESÚMENES}

Presentamos un análisis de la novela Juntacadáveres (1964) de Juan Carlos Onetti a partir de documentos manuscritos y dactiloscritos corregidos de puño y letra por el autor. En los manuscritos donde consigna el borrador redaccional, se observa que la copia, el pasado en limpio, impulsa la construcción narrativa : los primeros capítulos de la novela, esbozados con un lápiz negro en un cuaderno escolar, son reescritos luego en tinta azul. Por otra parte, las modificaciones entre una etapa y otra de inscripción son escasas, como si la copia de un registro estuviera destinada a afirmar una versión textual ; los sistemas de modificaciones observados entre una fase y las subsiguientes tienden a suavizar la descripción de los personajes, a moderar asperezas que rozan la crueldad : la matriz de los cambios estaría orientada por un sentimiento 
de mayor empatía hacia ellos, atemperando las expresiones denigrantes, que los dejaban muy expuestos a sus miserias.

L'article analyse le roman Juntacadáveres (1964) de Juan Carlos Onetti en partant des documents manuscrits et tapuscrits avec des corrections autographes de l'auteur. Dans les manuscrits où Onetti consigne le brouillon rédactionnel, on voit que la copie au propre impulse le développement narratif : les deux premiers chapitres du roman, ébauchés au crayon dans un cahier scolaire, sont réécrits à l'encre bleue. Par ailleurs, les modifications entre une étape de l'écriture et la suivante sont peu nombreuses, il semblerait que la copie vise à confirmer une version textuelle; les modifications observées tendent à adoucir la description des personnages, à modérer des rudesses qui frisent souvent la cruauté : la matrice de ces modifications est orientée par un sentiment d'empathie envers eux, et cherche à modérer les expressions dénigrantes qui les exposaient à leurs misères.

We will consider the analysis of the writing processes in Juan Carlos Onetti's novel Juntacadáveres (1964), focusing our work on documents, manuscripts and typescripts corrected by hand by the author himself. In the manuscripts where he drew up chapters 1 and 2, we observed that in the process of rewriting and cleaning prior versions, the author seems to reaffirm, and give impulse to, the building of the plot. The first chapters of the novel, first sketched in a copybook in black pencil, are then rewritten in blue ink. On the other hand, variants between one and another step are rare, as if the copy were oriented to affirm a version; the variations that can be found have a tendency to temper the description of characters, to mitigate their rudeness, which is often near to cruelty : the variants in the writing processes are oriented by an increasing feeling of empathy towards the characters, which is seen by means of softening the cruel phrases showing their miseries.

ÍNDICE

Mots-clés: Genèse, incipit, copie, réécriture, atténuation

Keywords: Genesis, copy, rewriting, fading

Palabras claves: copia, reescritura, atemperación

\section{AUTOR}

\section{MARÍA ALEJANDRA ALÍ}

Universidad de Buenos Aires

malejandra_ali@yahoo.com; maali@filo.uba.ar 